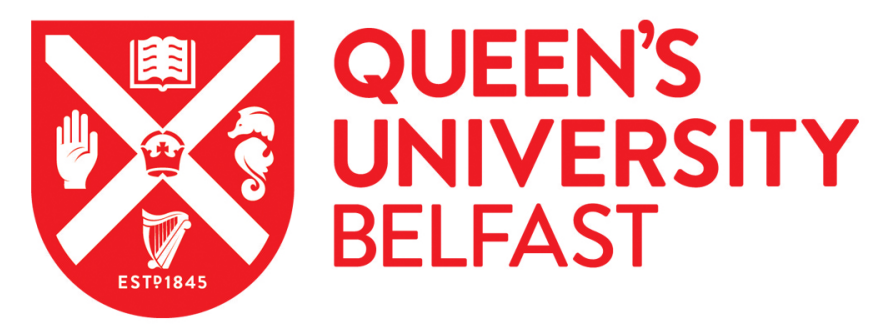

\title{
Fostering Harmony and Dealing with Difference in Education: A Critical Review of Perspectives on Intergroup Relations
}

Hughes, J., Loader, R., \& Nelson, J. (2018). Fostering Harmony and Dealing with Difference in Education: A Critical Review of Perspectives on Intergroup Relations. In A. Keet, \& M. Zembylas (Eds.), Critical Human Rights, Citizenship, and Democracy Education (pp. 123-138). Bloomsbury Academic.

\section{Published in:}

Critical Human Rights, Citizenship, and Democracy Education

\section{Document Version:}

Peer reviewed version

Queen's University Belfast - Research Portal:

Link to publication record in Queen's University Belfast Research Portal

\section{Publisher rights}

Copyright 2018 Bloomsbury. This work is made available online in accordance with the publisher's policies. Please refer to any applicable terms of use of the publisher.

\section{General rights}

Copyright for the publications made accessible via the Queen's University Belfast Research Portal is retained by the author(s) and / or other copyright owners and it is a condition of accessing these publications that users recognise and abide by the legal requirements associated with these rights.

Take down policy

The Research Portal is Queen's institutional repository that provides access to Queen's research output. Every effort has been made to ensure that content in the Research Portal does not infringe any person's rights, or applicable UK laws. If you discover content in the Research Portal that you believe breaches copyright or violates any law, please contact openaccess@qub.ac.uk. 


\title{
Fostering Harmony and Dealing With Difference in Education: A Critical Review of Perspectives on Intergroup Relations
}

\author{
Joanne Hughes, Rebecca Loader \& James Nelson
}

The purpose of this chapter is to consider theoretical perspectives on intergroup relations with respect to human rights, democracy and citizenship education. The first part of the chapter therefore provides an overview of four major theoretical frameworks that have emerged within the discipline of social psychology to explain the development of intergroup inequality, prejudice and conflict. Noting that research into human rights, democracy and citizenship education has not engaged substantially with these theories, we argue for their more extensive application in this field. The second part of the chapter focuses on intergroup contact theory, which has received more substantial attention in education as a model for fostering intercultural understanding and dialogue. Following an outline of the contact hypothesis and its influence in educational settings, particularly in Northern Ireland, we discuss recent work that raises queries about the contribution of contact-based approaches to equality and social justice. In particular, we will focus on the apparent tension between fostering harmony and exploring difference (and associated issues of conflict, discrimination and inequality) during intergroup encounters: while contact theory tends to prioritize the former, critical educationalists have stressed the importance of the latter to enhance democratic capability, promote respect for diversity and human rights, and transform social relations. Drawing on our own research, we consider how this tension has been manifest in 
education in Northern Ireland, and reflect on a potential way forward offered by a model for shared education.

\section{Intergroup theory}

The field of social psychology has made a major contribution to the theoretical understanding of intergroup conflict and prejudice. Of theories emerging in this field, perhaps the most enduring is social identity theory (SIT) (Tajfel and Turner 1979). Positing membership of social groups (such as one's religious group, gender or sports team) as central to self-concept and self-esteem, SIT states it is psychologically important that the groups to which one belongs are 'positively differentiated or distinct from the relevant outgroups' (Tajfel and Turner 1979: 40). To ensure this distinctiveness, individuals employ a range of strategies to enhance or maintain their group's status relative to others: - favouring the ingroup, denigrating or discriminating against the outgroup, and engaging in intergroup competition or even conflict (van Oord 2008; Tajfel and Turner, 1979; Wolfe and Spencer 1996).

While social identity theory has been influential in the field of intergroup relations, a number of researchers have criticised its neglect of group power and outgroup favouritism and advanced two further accounts: social dominance theory (SDT) and system justification theory (SJT) (Jost, Banaji and Nosek 2004; Sidanius et al. 2004). According to SDT, discrimination is made possible by the existence of shared ideologies that legitimize the inequitable distribution of power and resources by individuals and institutions. The extent to which individuals endorse these ideologies depends, in part, on the strength of their 'social dominance orientation' (SDO), that is, their desire for group-based dominance (Sidanius et al. 2004). Proponents of SJT similarly posit the existence of legitimating social ideologies, but argue further that unequal systems benefit from 'the social and psychological needs' of 
individuals, including members of disadvantaged groups, to legitimise the status quo 'as good, fair, natural, desirable, and even inevitable' (Jost, Banaji and Nosek 2004: 887).

A fourth framework for the analysis of hostilities between groups, intergroup threat theory (ITT) (Stephan, Ybarra and Rios 2015), brings together theories of realistic group conflict and symbolic racism (Riek, Mania and Gaertner 2006). According to ITT, negative intergroup attitudes can arise from the perception that an outgroup poses a threat to the physical and material wellbeing of group members ('realistic threat') or to their culture and way of life ('symbolic threat') (Stephan, Ybarra and Rios 2015). Perceptions of such threats can provoke negative emotions and behaviours, including fear, prejudice, avoidance and aggression. Individuals most apt to perceive intergroup threats include those who identify strongly with the ingroup, hold negative views of the outgroup or have limited experience of intergroup contact (Stephan, Ybarra and Rios 2015).

Seeking a deeper understanding of intergroup conflict, inequality and discrimination, these theories have considerable consonance with, and relevance to, education for democracy, citizenship and human rights. They may inform the content and delivery of educational programmes or provide a lens through which to evaluate existing curricula, resources and pedagogies. Research in this vein might consider, for example, to what extent citizenship education endorses or challenges system justification and its underpinning ideologies, or how human rights education addresses contemporary discourses regarding the 'threat' posed by ethnic others. To date, however, educational research and practice that engages directly with these social psychological theories has been limited - a situation that deserves redress, not least because what exists has generated valuable insights. Studies informed by social identity theory have found, for example, that identity strength may influence teachers' willingness to collaborate across ethno-religious lines (Donnelly 2012) and inform their teaching on citizenship and identity in ways that reproduce conflict (Korostelina 2015). Moreover, 
research informed by intergroup threat theory has found that perceptions of threat can negatively influence young people's experiences of day-to-day encounters with outgroup members (van Acker 2014), while social dominance researchers report that those high in SDO are more likely to oppose inclusive educational practices (Crowson and Brandes 2010).

Intergroup contact theory

While research and practice in citizenship and democracy education has not engaged extensively with social psychological theories of inequality and prejudice development, there has been greater interest in theories of prejudice reduction. Particularly notable within this work has been the use of intergroup contact theory, which has informed both research and practice in improving relations in educational settings. As set out by Allport (1954), the contact hypothesis states that a positive encounter with a member of a negatively stereotyped group should improve an individual's attitudes to the group as a whole, providing four facilitating conditions are present: equal status between group members, cooperation, common or superordinate goals, and support from relevant authorities. Subsequently, researchers have proposed a fifth 'condition' of contact: that the encounter should provide opportunities for participants to become acquainted - what Pettigrew (1998) terms 'friendship potential'.

Since its formulation, the contact hypothesis has received considerable attention from researchers seeking to test whether and under what circumstances contact can improve attitudes. With a meta-analysis of 515 studies providing strong empirical support for the effects of contact across different countries, populations and settings, including education (Pettigrew and Tropp, 2006), research has increasingly focused on the process by which contact reduces prejudice. This has identified key mediators of contact, including anxiety and 
empathy (Pettigrew and Tropp 2008), and numerous moderators, such as prior outgroup attitudes, identity strength and relative group status (Graham, Frame and Kenworthy 2014; Tausch et al. 2007). Research also suggests that the salience of separate identities and the perceived typicality of outgroup members during the encounter can help ensure that changes in attitude generalise to the outgroup as a whole (Brown et al. 2007). Recent work has examined the impact of negative contact, suggesting that adverse encounters have a more substantial and consistent effect on intergroup attitudes than positive experiences (Barlow et al., 2012; Graf, Paolini and Rubin, 2014). While the greater prevalence of favourable encounters (at least in peaceful societies) ensures a net positive impact of contact (Graf, Paolini and Rubin 2014), this underlines that contact per se is no guarantee of successful outcomes.

Intergroup contact and its application in educational settings

The provision of opportunities for contact within schools and colleges has been advocated on both civic and educational grounds (Williams 1998): first, as preparation for living and working alongside those from different religious and cultural backgrounds as adults, and second, as crucial for learning about diversity and developing respect for difference. Contact has also been recognised as a precursor to intergroup dialogue, which aims to promote 'understanding of social identities and of social inequalities and conflicts... and to build individual and collaborative capacity for change' (Nagda et al. 2013, p.211-12). To these ends, measures facilitating contact have taken a number of forms, from short-term 'encounter' programmes to the wholesale desegregation of schools (Maoz, 2011; Schofield, 1991). In our own context of Northern Ireland, where more than 90 per cent of pupils attend separate Catholic or Protestant schools (Department of Education, 2017), both contact 
schemes and integrated schools have been notable features of the education landscape over the past 35 years. While the former have typically brought together pupils from separate schools for short-term activities or excursions (O’Connor, Hartop and McCully, 2002), the latter have aimed to provide more sustained contact in institutions with an explicitly integrated ethos (Northern Ireland Council for Integrated Education, 2012). Since 2007, a third initiative has been developed to promote contact via inter-school collaboration. In this approach, known as 'shared education', schools form partnerships across denominational lines to provide lessons and activities for mixed groups of students (Gallagher 2016). Pupils move between the schools to attend these shared classes, which are delivered regularly over a year or more.

Research into school-based contact in Northern Ireland has identified generally positive outcomes, providing contact is of sufficient duration. While one-off meetings via school contact schemes have had limited impact (O'Connor, Hartop and McCully, 2002), the frequent, sustained contact offered by integrated and shared education appears more effective. Relative to peers attending denominational schools, current or former pupils of integrated schools report more positive attitudes towards the other group, more moderate positions on political issues, and greater respect for the other group's culture and religion (Hughes et al. 2013; Hayes, McAllister and Dowds 2013; Stringer et al. 2009). Statistical analysis suggests that these differences are attributable to the regular and positive contact experienced by pupils at mixed schools (Hughes et al. 2013; Stringer et al. 2009). Moreover, pupils attending schools involved in shared education report higher numbers of cross-group friendships than those at non-participating schools, which in turn is associated with less anxiety about interaction and more positive intergroup attitudes (Hughes et al. 2010, 2012). 


\section{Critique of Intergroup Contact Theory}

The examples above showing successful outcomes from contact research suggests a natural fit between contact theory and those working in citizenship, democracy and human rights education, especially in programmes which engage learners in meetings and encounters across boundaries. Yet, the relevance of contact theory as an interpretive lens for such encounters in educational contexts is contested. Notions of plurality, multiculturalism and diversity have varied significantly from Allport's time (Kincheloe and Steinberg, 1997) and so too have the justifications for education for human rights, democracy and citizenship (Roth and Burbules 2007). Significant among these has been the work of critical education theorists who have been forthright in challenging a taken-for-granted neutralist-tolerant framework (Strandbrink 2014) which ignores issues of power in group-relations (Apple 2015). Critics assert that contact theorists have not kept pace with research areas of overlapping interest such as critical anti-racism (Erasmus 2010) and that their work has become 'self-referential' (Connolly 2000, 171).

In exploring the nature of the particular challenges presented to inter-group contact theory by critical education, it is possible to highlight four significant tensions. First, is the difference in aims between contact approaches and critical education - that is, whether the primary purpose in bringing learners together is to foster harmony or explore differences. Contact theory is premised on the improvement of relations and the implied assumption that, as a result of meeting under certain conditions, outgroup prejudice and ingroup bias will be reduced amongst participants. Arguably, it is a view aligned with liberal multiculturalism (Kincheloe and Steinberg 1997) and a co-existence model which emphasizes universal values and common needs as the grounds for sharing and mutual understanding. The difficulty is that where the promotion of harmony is the goal, encounters can produce silence and avoidance or even the suppression of difference. In the context of encounters between Israeli 
Jews and Palestinians, Maoz (2011) asserts that contact characterized by a desire for coexistence can be counter-productive to the improvement of relations and Helman (2002) found evidence that even sustained contact in the same context can reproduce group inequalities when issues of power are ignored. Similarly, in a study of integrated schools in Northern Ireland, Donnelly (2008) found that teachers who emphasized same-ness in intergroup encounters, adopted a non-confrontational approach with students and avoided dealing with difference were likely to impede inter-community relations. The resistance to dealing directly with conflict related issues amongst teachers arose, in part, from a public sector culture of accountability and performativity, which meant the teachers understood their role in more instrumentalist terms.

By contrast, critical education is concerned with exploring difference in multilayered and explicit ways. From a critical multiculturalist perspective, dealing with difference must begin with the recognition that power is unequally shared (Nieto 2000) and that education is not neutral (Kincheloe and Steinberg, 1997), including education that has the intention of developing mutual understanding through inter-group contact activities. Further, a critical approach requires learners to become aware of the labels used to identify differences between their groups and to question their validity. To fail to do so, from the critical educator's perspective, provides tacit approval and legitimizes the labels or categories (Erasmus 2010; Gillespie, Howarth, and Cornish 2012). Thus contact theorists are accused of essentialism and adopting uncritical assumptions about categories which they presume to be fixed.

Second, is a difference of emphasis between the individual and the structural. Contact theory stands accused of theoretical individualism (Connolly 2000; Dixon, Durrheim, and Tredoux 2005) on the grounds of its internal logic: if the solution to the sources of societal division (racism, sectarianism, etc.) lies in changing attitudes and behaviours at the 
individual level then its causes must also lie there in the prejudices and stereotypes that individuals hold. In other words, the impact of structural and government level interventions is minimized. McEvoy, McEvoy and McConnachie (2006) suggest this was the case in Northern Ireland during the 1970s and 1980s when contact schemes between Catholic and Protestant young people were promoted and generously funded by the British government but failed to meet the expectations placed upon them because of a blindness to wider issues of justice and equality. Similarly, in studies of contact programmes in Israel, Maoz (2011) identified the prevalence of a 'co-existence model' which tended to reproduce structural inequalities between the groups of Israeli Jews and Palestinians.

By contrast, critical educators emphasize the need for the distribution of justice at a structural level. Where there is unequal access to justice and equality within the state or the education system more specifically, an emphasis upon the individual may, at best, be ineffective and, at worst, reinforce the unjust structures. Education must, therefore, proceed in a way that raises learners' awareness of the reality of power and the political nature of education. Choices made by educators around encounters between divided groups should be understood not as technical arrangements but as pedagogical events which are inevitably imbued with issues of equality, identity and agency (Giroux and Giroux 2006). Learners must be equipped with the tools and skills to deal with differences beyond the individual level, 'to prepare themselves for what it means to be critical, active citizens in the interrelated local, national, and global public spheres' (Giroux and Giroux 2006: 48).

A third tension can be seen in differing perspectives on processes of change when groups come into contact with one another, that is, between reform and revolution. Within research informed by contact theory, there is a general tendency towards gradual change and reform, reflected in recommendations for adjustments to the nature of contact and the environment in which it takes place. In particular, researchers typically demand more 
attention be given to Allport's conditions of contact noted above. This points to an inherent conservatism at the heart of contact theory that draws boundaries around the limits of change. For a critical educator like Erasmus (2010), however, minor adjustments are insufficient; what is needed is a fundamental challenge to the status quo. In the context of race relations in South Africa, she brands contact approaches as 'timid' and questions their ability to offer a critique of systemic racism. Critical education, in contrast to contact theory, aspires to be transformative (Freire 1996). Transformation arises, firstly, out of awareness of injustice and/or inequality and in turn demands a response. The response is likely to be disruptive as it challenges dominant hegemonies such as taken-for-granted market forces in education (Howe 1992) or unexamined, crude concepts of identity (Gillborn 2006).

Fourth, and finally, there is a tension between the normative and the descriptive with respect to contact theory and critical education. Dixon, Durrheim, and Tredoux (2005) have identified an idealist tendency in the methodological approach of contact researchers, who employ experimental methods to explore optimal forms of contact in highly-controlled settings. Dixon and colleagues contest, however, that such approaches neglect two important elements: the participants' own constructions of the meaning of contact and the real life, mundane and often more subtle contact that occurs in everyday interactions. Critical education, by contrast, emphasizes the learners' lived realities. According to Apple (2015: 178), a primary task of the critical educator as researcher is to "critically examine current realities with a conceptual/political framework that emphasizes the spaces in which more progressive and counter-hegemonic actions can, or do, go on'. This was the work carried out by Freire (1996), for example, in his Pedagogy of the Oppressed. Critical researchers argue for a reorientation of the field, away from a preoccupation with contact under 'optimal conditions' towards the 'stark realities of intergroup relations in everyday settings' (Dixon, Durrheim, and Tredoux 2005: 709). 
To conclude, the four tensions highlighted here indicate that educators should beware of making naive assumptions about the inherent good of intergroup contact and take care to consider issues of context, power and identity when bringing learners into contact through citizenship and human rights education. Where encounters between individual learners happen, they should accompany initiatives at a wider structural level; where intergroup power differentials may impact on relations between group members, they should be acknowledged and attempts made to mitigate them; where pedagogical aims for contact are constrained to 'getting along' and reconciling around commonalities, the potential power of education to deal with controversial issues should be exploited and opportunities for transformative action harnessed. In what follows, examples are provided of how one contact programme in Northern Ireland has sought to develop in these ways.

\section{Implications for interventions in education}

Northern Ireland presents an interesting context for reflection on the implications of the tensions noted above for interventions in education that aim to build intergroup relations. As we highlight, approaches adopted in the early years of the conflict, and based on the type of contact that valorises more harmonious relations between Catholics and Protestants have had limited effect. Short-term contact schemes, whilst perhaps symbolically important, sometimes reinforced stereotypes and were generally characterized by avoidance norms, with teachers adopting a 'light touch' approach to dealing with controversial issues (O'Connor, Hartop and McCully 2002). Integrated education has had a positive impact in respect of enabling crossgroup friendships and prejudice reduction (Stringer et al. 2009), but, despite considerable capital support from Government, it accounts for only $7 \%$ of the overall provision in Northern Ireland. Moreover, no Catholic school has ever transformed to integrated status, 
despite the legal option to do so. Speculation as to why integrated education remains only a niche sector, despite regular public surveys finding that a considerable majority of adults support the approach and profess it as a desirable option for their children, centres on arguments that resonate with tenets of critical education. Primarily, in a divided society, where historical inequalities between Catholics and Protestants were arguably somewhat levelled through an education system that offered Catholics in particular, a route out of poverty and disadvantage, and where cultural and religious identities are protected through distinctive school ethos and practices, schools are likely to be cherished sources of cultural empowerment. The disparity in survey findings, where the expressed intention towards integrated education is inconsistent with schools ultimately selected, may therefore reflect tension between perceived pressure to respond positively to an educational approach that promotes social harmony, and an understanding of the political, cultural and power relations that are embedded in separate education (Hughes and Loader 2015).

Although the tensions between critical education and contact theory are hardly likely to be reconcilable through any single intervention, we believe the model of school collaboration through 'shared education', introduced in Northern Ireland in 2007, has much to offer, not just in Northern Ireland but also in other divided societies that seek to promote social cohesion through schools. Based on evidence emerging over the last decade, we propose the following as justification for this position.

Unlike previous contact initiatives which foreground contact as a means of reducing prejudice and promoting more positive intergroup relations, the shared education initiative offers a range of educational opportunities for participating pupils and teachers. These include: extending the range of curriculum based subject choices for pupils, who can avail of the options on offer not just in their own school, but in partner schools; sharing of resources and expertise between partner schools; teacher exchanges that extend opportunities for 
teachers who might otherwise be limited to working within one denominational sector; and access to additional resources for smaller schools on the edge of viability due to low enrolment - particularly important in Northern Ireland, where the continued existence of small Catholic and Protestant communities within particular villages or towns may depend on accessibility of denominational schools.

Whilst educational opportunities created by shared education may contribute to the mitigation of disadvantage experienced by one community or the other, the approach also potentially meets social cohesion objectives by engaging pupils and teachers in extended interaction with those from a different community background. For many participants, such opportunities may not otherwise have been available, and as noted above there are benefits, including prejudice reduction, increased out-group trust and reduced levels of out-group anxiety. Relatedly, shared education creates a space for the exploration of group differences and critical inter-group dialogue, as advocated by Giroux and Giroux (2006) and others. Duffy and Gallagher (2017) for example, highlight how shared education has facilitated the exploration of contested terriory in Northern Ireland's second largest city, with pupils in partner schools engaging in dialogue on the origins and implications of Catholic preference to refer to the City as Derry and Protestant proclivity for the title Londonderry. They also demonstrate how shared education in the same city has helped promote more positive engagement between schools and statutory agencies, highlighting, in particular, the evolving relationship between the partnership's Catholic schools and the Police Service of Northern Ireland (PSNI). This represents a significant development in a context where the relationship between the police and the Catholic/nationalist community has historically been poor. In a similar qualitative study of shared education partnerships, Hughes (2014) reports the significant benefits of schools' engagement on a cross-community basis with 'local community elites', including clergy, local councillors and political representatives, and the 
facilitation of inter-community dialogue events, including a political forum hosted by one of the schools that brought representatives from rival parties together for a Q\&A session with pupils.

Ultimately, shared education represents systemic change in Northern Ireland education. In making the boundaries between separate schools more porous, the approach generates a new space for creating cross-group relationships, and interrogating the historical and current differences that underpin inequality, disadvantage and conflict. Importantly, whilst there is recognition that shared education can lead to the development of new and cross-cutting identities, the model is seen as respectful of existing identity positions and the interpretive frameworks that underpin them, concurrently challenging crude and essentialist identity concepts. The extent to which the education system ultimately becomes more integrated will depend on the willingness of schools and their stakeholders to continue participation and/or to sustain the cross-sectoral partnerships when and if the funding for shared education expires. The model may be more slow burn than the arguably transformative advent of integrated schools more than 30 years ago, but it is no less a fundamental challenge to the status quo (see Erasmus 2010), in that the shared educaiton approach is normalizing cross-group education in Northern Ireland and giving agency to schools and their communities in respect of how far they are willing to embrace the model and its consequences.

In foregrounding access to educational opportunity over reconciliation outcomes, and by respecting the will of groups to retain a largely separate school structure, the shared education approach has generated nearly universal support in Northern Ireland, and a comprehensive mainstreaming programme is underway, supported by a Shared Education Bill (2016) and an associated policy framework. The model has also shown to be attractive in other conflict societies. Shared education initiatives inspired by the Northern Ireland model 
are currently being piloted in the Former Yugoslav Republic of Macedonia and Israel, and there are proposals for projects in Cyprus, Bosnia and Croatia. Although there are some well documented challenges associated with shared education, not least of which is the risk that the relationship-building focus might be subverted by the neo-liberal priorities of performance measurement and league tables that typify western education (Hughes et al. 2016), shared education, to some extent at least, bridges the gap between an essentialist and individualistic model of contact, and one that resonates with the aims of critical education to challenge dominant hegemonies and support the development of critical, active citizens. This is aptly demonstrated in Payes' (2017) assessment of the shared education project in Israel,

Examining the programme in light of the contact hypothesis and its conditions, clearly, the programme operates in conditions of unequal status: the supervisor is a Jew; the Jewish population is stronger in socioeconomic terms; Hebrew-speaking schools are higher achievers, and the common language of contact is Hebrew, the dominant language in Israel, which is spoken by Arabs as a second language and by Jews as a first language. However, the focus on common educational goals, promoted by shared learning, provided some degree of balance over these difficulties. Similarly to Northern Ireland, adopting the approach of shared education creates better conditions for meeting the provisions for effective intergroup contact. Thanks to the focus on educational goals, the programme enjoys the institutional support of the supervisor, involves Arab and Jewish principals and teachers equally in designing the shared learning, and gives a strong weight to the Arabic language as a carrier of culture, even if not as a common spoken language. Many of the school principals, who form the core group of the programme, also report the development of close personal relations as a result of the shared work (Payes, 2017, p.13) 
In summarising the value of the shared education model, which is predicated on the need for intergroup contact, against the tension that is held to exist between fostering harmony and exploring difference (and associated issues of conflict, discrimination and inequality), we propose the following: Inter-group contact through schools need not be 'soft' - the model has been shown to effect systemic and structural change in respect of how education is delivered to create opportunities for all, whilst at the same time acknowledging and respecting the differences that underpin separate schooling and presenting opportunity for engagement with the difficult and controversial issues that manifest in sectarianism and inter-group conflict. To this end, the approach has the potential to build the 'individual and collaborative capacity for change' (Nagda et al, 2013) that is deemed central in human rights, democracy and citizenship discourses. 


\section{References}

Allport, G. W. (1954), The Nature of Prejudice, Reading, MA: Addison-Wesley.

Apple, M. W. (2015), 'Understanding and Interrupting Hegemonic Projects in Education:

Learning from Stuart Hall', Discourse: Studies in the Cultural Politics of Education, 36 (2): $171-84$

Barlow, F. K., S. Paolini, A. Pedersen, M. J. Hornsey, H. R. M. Radke, J. Harwood, M.

Rubin and C. G. Sibley (2012), 'The Contact Caveat: Negative Contact Predicts Increased Prejudice More Than Positive Contact Predicts Reduced Prejudice', Personality and Social Psychology Bulletin, 38 (12): 1629-1643.

Brown, R., A. Eller, S. Leeds and K. Stace (2007), 'Intergroup Contact and Intergroup Attitudes: A Longitudinal Study’, European Journal of Social Psychology, 37 (4): 692-703.

Connolly, P. (2000), 'What Now for the Contact Hypothesis? Towards a New Research Agenda', Race Ethnicity and Education, 3 (2): 169-93.

Crowson, H. M. and J. A. Brandes (2010), 'Predicting Community Opposition to Inclusion in Schools: The Role of Social Dominance, Contact, Intergroup Anxiety, and Economic Conservatism', The Journal of Psychology, 144 (2): 121-144.

Department of Education (Northern Ireland) (2017), Enrolments by School Management Type: 2000/01-2016/7, Bangor: DENI.

Dixon, J., K. Durrheim and C. Tredoux (2005), 'Beyond the Optimal Contact Strategy: A Reality Check for the Contact Hypothesis', American Psychologist 60 (7): 697-711.

Donnelly, C. (2008), 'The Integrated School in a Conflict Society: A Comparative Analysis of Two Integrated Primary Schools in Northern Ireland', Cambridge Journal of Education, 38 
(2): $187-98$.

Donnelly, C. (2012), 'Defending Identity and Ethos: An Analysis of Teacher Perceptions of School Collaboration in Northern Ireland', Policy Futures in Education, 10 (5): 540-551.

Duffy, G. and A. Gallagher (2017), 'Shared Education in Contested Spaces: How Collaborative Networks Improve Communities and Schools', Journal of Educational Change, 18 (1): 107-134.

Erasmus, Z. (2010), 'Contact Theory: Too Timid for "Race” and Racism', Journal of Social Issues 66 (2): 387-400.

Freire, P. (1996), Pedagogy of the Oppressed, Harmondsworth: Penguin Books.

Gallagher, T. (2016), 'Shared Education in Northern Ireland: School Collaboration in Divided Societies', Oxford Review of Education, 42 (3): 362-375.

Gillborn, D. (2006), 'Critical Race Theory and Education: Racism and Anti-Racism in Educational Theory and Praxis', Discourse: Studies in the Cultural Politics of Education, 27 (1): 11-32.

Gillespie, A., C. Howarth and F. Cornish (2012), 'Four Problems for Researchers Using Social Categories', Culture and Psychology 18 (3): 391-402.

Giroux, H. A. and S. S. Giroux (2006), 'Democracy and the crisis of public education', in H.A. Giroux (ed), America on the Edge: Henry Giroux on Politics, Culture and Education, 43-52, New York: Palgrave Macmillan.

Graf, S., S. Paolini and M. Rubin (2014), 'Negative Intergroup Contact Is More Influential, but Positive Intergroup Contact Is More Common: Assessing Contact Prominence and 
Contact Prevalence in Five Central European Countries', European Journal of Social Psychology, 44 (6): 536-547.

Graham, H. E., M. C. Frame and J. B. Kenworthy (2014), 'The Moderating Effect of Prior Attitudes on Intergroup Face-to-Face Contact', Journal of Applied Social Psychology, 44 (8): $547-556$.

Hayes, B. C., I. McAllister and L. Dowds (2013), 'Integrated Schooling and Religious Tolerance in Northern Ireland', Journal of Contemporary Religion, 28 (1): 67-78.

Helman, S. (2002), 'Monologic Results of Dialogue: Jewish-Palestinian Encounter Groups as Sites of Essentialization', Identities: Global Studies in Culture and Power, 9 (3): 327-354.

Howe, K. R. (1992), 'Liberal Democracy, Equal Educational Opportunity, and the Challenge of Multiculturalism', American Educational Research Journal, 29 (3): 455-70.

Hughes, J. (2014), 'Contact and Context: Sharing Education and Building Relationships in a Divided Society', Research Papers in Education, 29 (2): 193-210.

Hughes, J. and R. Loader (2015), "Plugging the Gap": Shared Education and the Promotion of Community Relations through Schools in Northern Ireland', British Educational Research Journal, 41 (6): 1142-1155.

Hughes, J., C. Donnelly, R. Leitch and S. Burns (2016), 'Caught in the Conundrum: Neoliberalism and Education in Post-Conflict Northern Ireland - Exploring Shared Education', Policy Futures in Education, 14 (8): 1091-1100.

Hughes, J., C. Donnelly, M. Hewstone, T. Gallagher and K. Carlisle (2010), School Partnerships and Reconciliation: An Evaluation of School Collaboration in Northern Ireland, Belfast: Queen's University. 
Hughes, J., M. Hewstone, A. Campbell, S. Lolliot and T. Gallagher (2013), 'Inter-Group Contact at School and Social Attitudes: Evidence from Northern Ireland', Oxford Review of Education, 39 (6): 761-779.

Hughes, J., S. Lolliot, M. Hewstone, K. Schmid and K. Carlisle (2012), 'Sharing Classes between Separate Schools: A Mechanism for Improving Inter-Group Relations in Northern Ireland?' Policy Futures in Education, 10 (5): 528-539.

Jost, J. T., M. R. Banaji and B. A. Nosek (2004), 'A Decade of System Justification Theory: Accumulated Evidence of Conscious and Unconscious Bolstering of the Status Quo', Political Psychology, 25 (6): 881-919.

Kincheloe, J. and S. Steinberg (1997), Changing Multiculturalism, Buckingham: Open University Press.

Korostelina, K. (2015), 'Reproduction of Conflict in History Teaching in Ukraine: A Social Identity Theory Analysis', Identity, 15 (3): 221-240.

Maoz, I. (2011), 'Does Contact Work in Protracted Asymmetrical Conflict? Appraising 20 Years of Reconciliation-Aimed Encounters between Israeli Jews and Palestinians', Journal of Peace Research, 48 (1): 115-125.

McEvoy, L., K. McEvoy and K. McConnachie (2006), 'Reconciliation as a Dirty Word: Conflict, Community Relations and Education in Northern Ireland', Journal of International Affairs, 60 (1): 81-106.

Nagda, B.A., A. Yeakley, P. Gurin and N. Sorensen (2013), 'Intergroup dialogue: a criticaldialogic model for conflict engagement', in L.R. Tropp (ed) The Oxford Handbook of Intergroup Conflict, 210-228, Oxford: Oxford University Press. 
Nieto, S. (2000), 'Placing Equity Front and Center: Some Thoughts on Transforming Teacher Education for a New Century', Journal of Teacher Education, 51 (3): 180-187.

Northern Ireland Council for Integrated Education (2012), Statement of Principles, Belfast: NICIE.

O’Connor, U., B. Hartop and A. McCully (2002), A Review of the Schools Community Relations Programme, Bangor: Department of Education.

Payes, S (2017), 'Education Across the Divide: Shared Learning of Separate Jewish and Arab Schools in a Mixed City in Israel', Education, Citizenship and Social Justice, 1-17. Advance online publication. doi: 10.1177/1746197917698489.

Pettigrew, T. F. and L. R. Tropp (2006), ‘A Meta-Analytic Test of Intergroup Contact Theory', Journal of Personality and Social Psychology, 90 (5): 751-783.

Pettigrew, T. F. and L. R. Tropp (2008), 'How Does Intergroup Contact Reduce Prejudice? Meta-Analytic Tests of Three Mediators', European Journal of Social Psychology, 38 (6): 922-934.

Pettigrew, T. F. (1998), 'Intergroup Contact Theory', Annual Review of Psychology, 49: 6585.

Riek, B. M., E. W. Mania and S. L. Gaertner (2006), 'Intergroup Threat and Outgroup Attitudes: A Meta-Analytic Review', Personality and Social Psychology Review, 10 (4): 336353.

Roth, K. and N. C. Burbules (2007), Changing Notions of Citizenship Education in Contemporary Nation-States, Rotterdam: Sense Publishers. 
Schofield, J. W. (1991), 'School Desegregation and Intergroup Relations: A Review of the Research', Review of Research in Education, 17: 335-409.

Sidanius, J., F. Pratto, C. van Laar and S. Levin (2004), 'Social Dominance Theory: Its Agenda and Method', Political Psychology, 25 (6): 845-880.

Stephan, W. G., O. Ybarra and K. Rios (2015), 'Intergroup Threat Theory', in T.D. Nelson (ed), Handbook of Prejudice, Stereotyping, and Discrimination, 2nd edn, 255-278, New York: Taylor and Francis Inc.

Strandbrink, P. (2014), 'Fair and Cloudy Weathers of Tolerance in Civic and Religious Education in Northern Europe', Education, Citizenship and Social Justice, 10 (1): 3-20.

Stringer, M., P. Irwing, M. Giles, C. McClenahan, R. Wilson and J. A. Hunter (2009), 'Intergroup Contact, Friendship Quality and Political Attitudes in Integrated and Segregated Schools in Northern Ireland', British Journal of Educational Psychology, 79 (2): 239-257.

Tajfel, H. and J. Turner (1979), ‘An Integrative Theory of Intergroup Conflict', in W. Austin, and S. Worchel (eds), The Social Psychology of Intergroup Relations, 33-47, Monterey: Brooks/Cole.

Tausch, N., M. Hewstone, J. Kenworthy, E. Cairns and O. Christ (2007), 'Cross-Community Contact, Perceived Status Differences, and Intergroup Attitudes in Northern Ireland: The Mediating Roles of Individual-Level Versus Group-Level Threats and the Moderating Role of Social Identification', Political Psychology, 28 (1): 53-68.

Van Acker, K., K. Phalet, J. Deleersnyder and B. Mesquita (2014), 'Do “They” Threaten "Us" Or Do "We" Disrespect "Them": Majority Perceptions of Intergroup Relations and Everyday Contacts with Immigrant Minorities', Group Processes and Intergroup Relations, 17 (5): 617-628. 
Van Oord, L. (2008), ‘After Culture: Intergroup Encounters in Education', Journal of Research in International Education, 7 (2): 131-147.

Williams, K. (1998) 'Education and Human Diversity: the Ethics of Separate Schooling Revisited', British Journal of Educational Studies, 46 (1): 26-39.

Wolfe, C. T. and Spencer, S. J. (1996), 'Stereotypes and Prejudice: Their Overt and Subtle Influence in the Classroom', American Behavioral Scientist, 40 (2): 176-185. 